Anales de Literatura Hispanoamericana

ISSN: 0210-4547

\title{
El cuerpo en vilo: otro acercamiento a los cuentos fantásticos de Julio Cortázar
}

Margherita Cannavacciuolo ${ }^{1}$

Resumen. El artículo propone una nueva aproximación a la narrativa breve de Julio Cortázar a través del análisis sobre el papel del cuerpo humano como elemento catalizador de la dialéctica fantástica de la narración. El estudio se apoya en dos reflexiones preliminares: por un lado, la observación de que el cuerpo del personaje constituye un elemento intermedio y, por otro, de que el cuerpo se convierte en una instancia de mediación entre los mismos.

Palabras clave: Julio Cortázar; cuentos fantásticos; cuerpo humano.

[en] The body in vilo: another approach to the fantastic stories of Julio Cortázar

Abstract. The article proposes a new approach to Julio Cortázar's short story through the analysis of
the role of the human body as a catalyst for the fantastic dialectic of narration. The study is based on
two preliminary reflections: on the one hand, the observation that the character's body constitutes an
intermediate element and, on the other that the body becomes an instance of mediation between them. Keywords: Julio Cortázar; fantastic stories; human body.

Sumario. 1. Introducción. 2. Miradas hostiles y otras amenazas. 3. Artos rebeldes. 4. Piel a piel. 5. Hacia una poética de la disonancia.

Cómo citar: Cannavacciuolo, M. (2019) El cuerpo en vilo: otro acercamiento a los cuentos fantásticos de Julio Cortázar, en Anales de Literatura Hispanoamericana 48, 331-347.

\section{Introducción}

El presente estudio propone una nueva aproximación a la narrativa breve de Julio Cortázar a través de la reflexión sobre el papel del cuerpo humano como elemento catalizador de la dialéctica fantástica de la narración. A partir de la consideración de la imprescindible condición relacional del cuerpo (Merleau-Ponty [1945] 1994, Le Breton 2012), el análisis que aquí se propone se apoya en dos reflexiones preliminares. En primer lugar, la observación en que el cuerpo del personaje constituye un elemento intermedio (Lugnani 1983), ya que se ubica entre dos

1 Università Ca’ Foscari Venezia, Venezia. Italia.

E-mail: margherita.c@unive.it 
órdenes ontológicos de naturaleza diferente que se enfrentan en el relato -y que constituyen la estructura del relato fantástico-, es decir el construido según el paradigma de realidad y el fantástico; en segundo lugar, se convierte en una instancia de mediación entre los mismos (Bhabha 1994).

Coincido con el acertado planteamiento de Lászlò Scholz en su estudio "Una mística profana (Julio Cortázar y la literatura sin palabras)" del año 2000, acerca del recurso a los sentidos físicos como reacción contra el lenguaje verbal, cuyas estructuras tradicionales se consideran estériles en la visión del autor ${ }^{2}$. Sin embargo, mi hipótesis se mueve hacia la consideración del cuerpo no solo como una lengua alternativa, secundaria o, más bien, complementaria al "verbo racionalizado" (Scholz 2000: 87), sino, más bien, como mecanismo del que depende la actuación de la lógica y el efecto fantásticos. El cuerpo del personaje, en mi planteamiento, viene a ser el punto de fricción que anticipa y manifiesta la ambigüedad fantástica ya que considero los protagonistas de los cuentos fantásticos del autor argentino sujetos fronterizos en cuya piel, parafraseando las palabras de Eugenio Trías (1991: 48), se incrusta el límite entre los dos distintos órdenes ontológicos aludidos y se manifiesta el choque entre los mismos. En este sentido, el lugar intermedio ocupado por el cuerpo del personaje me permite pensar el cuerpo como función de la lógica fantástica; es decir, como vehículo del intercambio simbólico (Galimberti 2013) entre esos distintos niveles de realidad, de acuerdo con un proceso que culmina en la desposesión del cuerpo por parte del personaje.

Los relatos considerados en esta ocasión son "Ómnibus" (Bestiario 1951), "El ídolo de las cícladas" (Final del juego 1956) y "Cuello de gatito negro" (Octaedro 1974), dado que, a partir de la comunicación intersomática que se da entre los cuerpos de los personajes, se produce una capilarización del cuerpo en el texto que coincide con su semiotización. Así, el cuerpo se convierte en el sistema semiótico para expresar lo fantástico.

\section{Miradas hostiles y otras amenazas}

El cuerpo es el pivote de arraigo del hombre al tejido del mundo, afirma David Le Breton en Antropología del cuerpo en la modernidad (2012: 60), haciéndose eco de Maurice Merleau-Ponty que seis décadas antes, en su Fenomenología de la percepción (1945), había insistido en la continuidad entre la carne del cuerpo y la carne del mundo. A partir, por lo tanto, de la condición relacional del cuerpo sancionada por fenomenólogos y sociólogos, me apropio del concepto de intercambio simbólico, que Umberto Galimberti, siguiendo a Baudrillard ([1979] 1980), reconoce como característico de las sociedades tradicionales, entendido no solo como el medio que permite la "circulación de sentido" (35), sino sobre todo

\footnotetext{
${ }^{2}$ Scholz apunta al uso de los sentidos en la narrativa del autor como manera para reaccionar y deconstruir el lenguaje verbal. El apartado segundo del estudio citado versa sobre el sonido y el ruido como recursos narrativos y narratológicos, a la vez que como lenguaje sustitutivo del verbal, en algunos cuentos del autor "Casa tomada", "La puerta condenada" y "Verano"-; mientras que el tercero reflexiona acerca de la importancia del sentido del gusto en relatos como "Circe". De la misma manera, la cuarta parte se centra en los medios visuales en la narrativa del autor.

${ }^{3}$ Este cuento ha sido enfocado desde el punto de vista de la estructuración del "pasaje" en el estudio de Rosalba Campra (2009).
} 
como "zona en la que el sentido se expresa y en la que los individuos participan"4 (33). Dentro de esta dinámica, el cuerpo no se percibe como entidad anatómica, sino como relación social, con lo cual se sobrepasa la división tradicional entre materia y espíritu. Al mismo tiempo, uno de los aspectos del intercambio simbólico más sobresaliente para mi análisis es la ley de reversibilidad asociada al símbolo, que se opone a la lógica disyuntiva; es decir, no se admite ninguna línea de división que separe y excluya una realidad de la otra, sino que vida y muerte, sueño y vigilia, humano y bestial se vinculan mediante una relación de reciprocidad. El cuerpo se entiende, por lo tanto, como centro de irradiación simbólica donde todo se intercambia.

Es en este punto donde se vinculan, en mi hipótesis, cuerpo y fantástico, ya que el concepto de "transgresión" fantástica (Jackson 1986) puede realizarse también bajo la forma de intercambio simbólico - amenazante, siguiendo la intuición de David Roas (2001) - a través del cuerpo de los personajes; se produce una somatización del efecto fantástico, a raíz de la cual, por lo tanto, el cuerpo vehicula y exterioriza el "escándalo racional" que, según Campra (2008), caracteriza lo fantástico.

En los tres cuentos mencionados de Cortázar, dos elementos corporales son vehículo de la transmisión fantástica: las $\operatorname{manos}^{5}$ y la mirada ${ }^{6}$. La isotopía de la

${ }^{4}$ La traducción es mía.

${ }^{5}$ Las manos constituyen una obsesión temática que cruza toda la narrativa de Julio Cortázar adquiriendo distintos papeles y matices. Podemos contemplar su temprana aparición en los cuentos juveniles "Las manos que crecen" y "Estación de la mano" escritos entre 1937 y 1945 (La otra orilla 1994) su regreso en "No se culpe a nadie" (segunda edición de Final del juego 1964), "Siestas" (Último round 1969) donde aparece el motivo de la mano cercenada, sustituida por una mano de cera, y en "Las líneas de la mano" (Historias de cronopios y famas) donde figura la mano autónoma que volverá en "Cuello de gatito negro". Las manos cortadas del cuerpo de una mujer asesinada por la dictadura militar y puestas en un frasco son lo único que se les concede ver a la madre en "Recortes de prensa", y con un close up en las manos deseadas de Dilia acaba "Historias que me cuento" (Queremos tanto a Glenda 1980). La mano comida por la rata de la pequeña Laurita es la impactante imagen visual, y obsesión del protagonista Lozano, en "Satarsa" (Deshoras 1982). Aunque no se trata de un cuento fantástico, la mano como elemento demarcador que une y separa a una madre del hijo adolescente se encuentra en "Usted se tendió a tu lado" (Alguien que anda por ahí 1977). Las manos ocupan un lugar privilegiado también en Rayuela y 62, Modelo para armar. En la primera novela, la mano es para Oliveira el puente que permite rebasar los límites de la racionalidad y alcanzar el centro de "algo que otra ilusión infinitamente hermosa y desesperada había llamado en algún momento inmortalidad” (1979: 65); y en el capítulo setenta y seis se alude a la obsesión de Oliveira por las manos de Pola, y una vez más se subraya la idea de las manos como medio para franquear un límite: "usted movía esa mano como si estuviera tocando un límite y después de eso empezaba un mundo a contrapelo" (552). En el segundo texto, la obsesión de Juan por las manos de Frau Marta adquiere tintes inquietantes, ya que tienen algo de "lechuzas, de garfíos negruzos" (1995: 56) y se relacionan con las "maneras aracnoides" de la mujer (1995: 55). Para una profundización sobre la importancia de las manos en la narrativa del autor se remite al estudio de Malva E. Filer (1983), que ofrece también un recorrido por los antecedentes literarios del autor. Para otra perspectiva sobre el uso de las manos en "Cuello de gatito negro", se remite al estudio de René Prieto (1998), donde se analiza la presencia de símbolos, tales como el uso de las manos, desórdenes respiratorios, claustrofobia, temor a la oscuridad y túneles, que obsesionaron a Cortázar, en este y otros cuentos del autor. En este trabajo la fuente de sus obsesiones se sitúa en el trauma del nacimiento.

${ }^{6}$ Al par de las manos, también la mirada y su potencial hermenéutico es sumamente explotada en la narrativa del autor, conviertiéndose incluso en un recurso para vehicular la dinámica fantástica. Además de los cuentos que aquí se analizan, la mirada protagoniza relatos como "Áxolotl” (Bestiario 1951), "Silvia" (Último round 1969), "En nombre de Boby" (Alguien que anda por ahi 1977), por citar solamente algunos ejemplos dentro de la copiosa narrativa del autor; "Las babas del diablo" (Las armas secretas 1959) se construye sobre una telaraña de miradas cruzadas a las que se suma el ojo de la cámara de foto, así como "Graffiti" (Queremos tanto a Glenda) se basa en la dinámica del ver sin ser visto. Es importante, además, los juegos con los puntos de vista que caracterizan la narrativa del autor, baste con pensar en los puntos de vista ambiguos de los 
vista conforma la urdimbre narrativa de "Ómnibus". Al subir Clara al ómnibus 168 se dice que el guarda no le sacaba "los ojos de encima, como extrañado de algo" (CC I: 128$)^{7} \mathrm{y}$, después de haber tomado asiento, nota que "el conductor se dio la vuelta y también la miró, con trabajo por la distancia pero buscando hasta distinguirla muy hundida en su asiento. [...] los dos miraron a Clara, se miraron entre ellos" (CC I: 128-129). A partir de las ojeadas que el guarda y el conductor le dedican a la mujer ${ }^{8}$, se desencadena una telaraña de miradas hostiles que los otros pasajeros dirigen constante e insistentemente a Clara, que se condensa en el siguiente pasaje:

[Clara] observó de reojo a la señora del gran ramo de claveles que viajaba en el asiento de adelante. Entonces la señora la miró a ella [...] y Clara sacó un espejito y estuvo en seguida absorta en el estudio de sus labios y sus cejas. Sentía ya en la nuca una impresión desagradable; la sospecha de otra impertinencia la hizo darse vuelta con rapidez, enojada de veras. A dos centímetros de su cara estaban los ojos de un viejo de cuello duro, con un ramo de margaritas componiendo un olor casi nauseabundo. En el fondo del ómnibus, instalados en el largo asiento verde, todos los pasajeros miraron hacia Clara, parecían criticar alguna cosa en Clara que sostuvo sus miradas con un esfuerzo creciente, sintiendo que cada vez era más difícil, no por la coincidencia de los ojos en ella ni por los ramos que llevaban los pasajeros; más bien porque había esperado un desenlace amable, una razón de risa como tener un tizne en la nariz (pero no lo tenía); y sobre su comienzo de risa se posaban helándola esas miradas atentas y continuas, como si los ramos la estuvieran mirando. ${ }^{9}$ (CC I: 129)

La mirada se convierte en un instrumento inquisitorio y de castigo ${ }^{10}$ que hunde a Clara en un estado de profunda inquietud, "un fuego frío cayéndole de todas partes" (CC I: 131). El individuo queda desposeído de una parte de sí mismo, atrapado sin remedio a través del contacto de los ojos de los otros sobre sí. El esfuerzo creciente de Clara de responder a las miradas ajenas es una señal de la pérdida del dominio de su existencia; advierte su impotencia para escapar al juicio

narradores de "Circe" (Bestiario 1951) y "La salud de los enfermos" (Todos los fuegos el fuego 1966). Para una profundización del tema dentro de los últimos cuentos del autor, se remite al trabajo de Peter Frölicher (1995).

${ }^{7}$ De aquí en adelante todas las referencias a los textos de Julio Cortázar estarán tomadas de Cuentos Completos. III (2015) que se abreviará en CC I y CC II.

${ }^{8}$ En este sentido, a pesar de que, en línea general, el estudio brindado por Armando Pereira del cuerpo adolescente en los relatos de Cortázar (2005: 37-127) me parece digno de interés, no coincido con el análisis del cuento que el crítico propone (37-40), ya que el relato se encara a partir de la dialéctica entre mirada adulta (la de los pasajeros) y cuerpo adolescente (el de Clara y del joven), ya que el texto no brinda ningún elemento que permita identificar a los dos protagonistas como dos adolescentes. El planteamiento del crítico se pone en tela de juicio gracias a una lectura atenta del texto mismo, ya que cuando el protagonista masculino hace su entrada en la historia, se alude a él como "el hombre" ("El hombre ascendió ágilmente, enfrentando al guarda que lo esperaba a medio coche [...]. El hombre tenía veinte centavos e la derecha [...]", CC I: 130). Aunque más adelante se afirma que "en realidad era joven, aunque tenía marcas duras en la cara" (CC I: 130), no hay elementos suficientes que avalen con certeza la hipótesis del crítico.

${ }^{9}$ El énfasis es mío.

${ }^{10}$ En este sentido, la mirada funciona según Pablo Brescia como uno de los tres vértices en los que se articula la relación pasajeros-conductores, donde los otros dos serían las flores y la actitud hostil (2011: 194). 
y a la extrañeza implicadas en esas miradas hostiles. Si la mirada deja sentir la desnudez del rostro (Le Breton 1999: 197), sacar el espejito y mirarse en él es una tentativa de Clara de reapropiarse de su rostro y, de este modo, recuperar su libertad. Sin embargo, este gesto tampoco le sirve a la joven para romper el hechizo, sino que es una acción que cae en el vacío de significación. Las miradas constantes e insistentes de los pasajeros se insinúan en sus mismos actos y le devuelve a la joven, parafraseando a Sartre, la solidificación y la alienación de sus propias posibilidades (1966: 309). El cuerpo de la joven se borra en las miradas ajenas.

Cuando un joven sube al ómnibus, se dice que tiene que enfrentar "al guarda que lo esperaba a medio coche mirándole las manos" (CC I: 130). Queda aquí sellada la oposición miradas-manos que, a partir de ese momento estructurará narratológicamente el relato. Las manos vacías de Clara y del joven se revelan ser las razones de las insistentes y contrariadas miradas de los pasajeros, tanto que cuando todos bajan en la parada de Chacarita, "los dos se miraron las manos. Estaban ahí, eran simplemente manos; nada más" (CC I: 132).

Las manos se convierten en metáfora ambivalente ya que, por un lado, representan la culpa de los personajes por no llevar flores, lo que justifica la ira de los demás, ellos no están participando en el rito, en la convención que une secretamente a los demás pasajeros; y, por el otro, se convierten en una zona de seguridad para los dos desaventurados, en donde ampararse frente a las miradas crueles: "Clara sintió que el muchacho posaba despacio una mano en la suya, como aprovechando que no podían verlo desde adelante. Era una mano suave, muy tibia, y ella no retiró la suya [...]" (CC I: 132). Más adelante, como para hacer frente a la rabia creciente del conductor y del guarda, las manos y los dedos de los protagonistas se aprietan, hasta que "el pasajero puso la otra mano sobre la rodilla de Clara, y ella acercó la suya y ambos se comunicaron oscuramente por los dedos, por el tibio acariciarse de las palmas" (CC I: 134). En este sentido, las manos se apropian del paradigma de reciprocidad destinado a las miradas; el intercambio que se genera entre ellas pone frente a frente a los dos jóvenes, ya que reproduce aquella reciprocidad inmediata, más pura que puede haber, que según Simmel $(1977,2014)$, se debe a la mirada. La percepción inmediata que el uno tiene de la otra ya no es visual, sino táctil. Una vez más, el cuerpo se yergue como infralengua que rebasa el lenguaje verbal. Como nota Pablo Brescia, en este cuento lo irracional no se da fuera del marco racional, sino que aparece como su exacerbación (2011: 193). Es decir, todo se rige según las reglas, se debe llevar ramos de flores y se debe ir a Chacarita, presentadas como condición necesaria hasta el extremo de llegar a la violencia si no se cumplen. El billete es el salvoconducto para el lado racional de la realidad, mientras que las flores son la contraseña secreta para el otro orden.

El miedo por la tensión de la escena y el crescendo de lo siniestro se expresa a través de la imagen de los dedos que se aprietan cada vez más; se lee que las manos del pasajero "se cubrieron de huesos salientes, de venas rígidas" y que Clara "contempló esos objetos macizos con una humilde confianza casi perdida bajo el 
terror" (CC I: 135) ${ }^{11}$. Las manos entrelazadas de los protagonistas tienen una función de defensa, ya que recrean una situación de intimidad donde arrojarse para hacer frente a la extrañeza hostil que procede de las miradas de los demás. A través del juego entre miradas y manos, el cuerpo se exterioriza en el texto, vehiculando la gradual desestabilización del paradigma de realidad.

\section{Artos rebeldes}

Si "Ómnibus" se rige sobre el conflicto entre miradas hostiles vs las manos protectoras, "Cuello de gatito negro" se desarrolla alrededor de la misma pareja oximorónica pero con una axiología invertida, ya que la amenaza fantástica reside precisamente en las manos de Dina animadas de vida propia ${ }^{12}$, y las miradas sirven, en cambio, como instrumento de vigilancia tranquilizadora. Es la mirada que asegura el dominio sobre las manos rebeldes y, por lo tanto, representa para los personajes, y por ende el lector, la seguridad de estar todavía del lado conocido y cognoscible de la realidad.

En el laberíntico metro de París, Lucho y Dina entran en contacto a través del roce de sus manos en la barra metálica del vagón. Se descubrirá, a pesar de la inicial incredulidad del joven, que la chica no puede controlar sus manos, que actúan por sí solas. Empieza un diálogo entre los dos, caracterizado por afirmaciones enigmáticas de Dina, que aluden a "ellas" (CC II: 113) -sus manoscomo responsables del contacto: "-No se puede hacer nada- repitió la chica. No entienden o no quieren, vaya a saber, pero no se puede hacer nada contra" (CC II: 114). El verbo "querer" atribuido a las manos subraya la existencia de una voluntad autónoma de las manos con respecto a la del sujeto al que pertenecen.

A pesar del estado de sutil inquietud que Lucho advierte en el metro, acepta este primer extraño contacto como un juego de seducción femenina. Los dos descienden del metro y se dirigen al piso de ella. De los diálogos inacabados entre los dos personajes y de las declaraciones misteriosamente alusivas de Dina se confirma la existencia de una presencia ominosa que angustia a la joven. Después de tener un encuentro sexual a oscuras, la mujer reclama insistentemente la luz. Si la oscuridad ha permitido la unión de los cuerpos porque ha ocultado lo abominable y lo innombrable que reside en Dina, recortando una ilusión de "normalidad" dentro de la extrañeza, la repetida petición de encender la luz expresa también la necesidad desesperada que la mujer advierte de vigilar sus manos.

\footnotetext{
${ }^{11}$ Entre las diversas lecturas que la crítica ofrece sobre el relato (Brescia 2011: 204), estudios como los de Antonio Plannells (1979) y Jaime Concha (1982), han leído el cuento en términos freudianos y junguianos, viendo en estos contactos entre los protagonistas del cuento una sexualización de la mano, y aludiendo a la pérdida de virginidad de la joven, así como al ómnibus como símbolo de deseo sexual. Sin embargo, Plannells cita una carta de Cortázar fechada 1977 donde se rechaza la interpretación del cuento en términos de defloración (1979: 177). Adoptando el mismo enfoque psicoanalítico, también "Casa tomada" ha sido interpretado como una radiografía fetal: los ruidos representarían los dolores del parto, la expulsión de los hermanos el parto mismo y el hilo de lana de Isabel el cordón umbilical (Andreu 1968: 62-63).

${ }^{12}$ Además de ser un motivo frecuentemente explotado por la literatura fantástica (Gerard de Nerval, Maupassant y Sheridan Le Fanu, por ejemplo), las manos “capaces de vida independiente" pueblan los terrores y los sueños personales de Julio Cortázar (Picon Garfield 1975: 145).
} 
En este sentido, es importante notar que en "Cuello de gatito negro" las miradas son ambivalentes ya que funcionan a la vez como instrumento de vigilancia pero también de rechazo; Dina quiere mirar, y por lo tanto controlar, sus manos, pero al mismo tiempo dentro del metro parece ignorar las iniciativas que sus manos toman de tocar las de Lucho. La indiferencia aludida se debe al hecho de que en la mirada reside también el estatuto de existencia del objeto mirado, con lo cual mirar la rebeldía de sus miembros coincide con legitimar la existencia de lo abyecto. El intercambio se cumple dentro del mismo cuerpo del personaje, ya que este recupera su ambivalencia simbólica, es decir, funciona como arraigo dentro de una dimensión ontológica conocida, y por lo tanto prueba de la existencia de dicha dimensión (mirada), pero también como umbral para acceder a otra dimensión amenazadora en cuanto imposible de conocer (manos).

La gradual debilidad de las miradas de los personajes -matizadas también en la oposición luz-oscuridad- marca el desarrollo narratológico del relato, ya que no pueden y no logran controlar la cada vez más creciente rebeldía de las manos que salen de todo cauce.

Sin embargo, se dice que la mano de Dina había doblado para abajo el fósforo "para quemarse y quemarla [...] pero después del segundo fósforo aplastado entre los dedos, cangrejo rabioso quemándose con tal de destruir la luz, entonces Dina había tratado de encender un último fósforo con la otra mano y había sido peor [...]. No te das cuenta que no quieren[las manos], es otra vez (CC II: 121). Lo fantástico coincide en el cuento con lo abyecto según la formulación de Julia Kristeva, ya que la identidad de Dina coincide con "la pérdida inaugural fundante de su propio ser" (2004: 12); para decirlo con una paráfrasis de Kristeva, la mujer encuentra lo imposible en sí misma: cuando encuentra que lo imposible es su ser mismo. En este sentido, la mujer no sufre una metamorfosis a lo largo de la narración, pasando a ser otra cosa, sino que la otredad ya reside en su misma naturaleza y empieza a revelarse desde el comienzo como ambivalencia amenazadora. En esta línea, el cuerpo de Dina parece reproducir aquel complexio oppositorum que Karoly Kérényi atribuye a las figuras míticas de la alteridad; de la copresencia simultánea de tratos humanos e inhumanos, que caracteriza este complejo, procede su rasgo intimidatorio y extrañante.

La dialéctica entre lo propio y lo ajeno que Dina reconoce en su misma mano es la misma que experimenta el protagonista de "No se culpe a nadie" (Final del juego) quien, tras haber forcejeado para salir del pulóver donde había quedad atrapado, entreabre los ojos y ve "cinco uñas negras suspendidas apuntando a sus ojos, vibrando en el aire antes de saltar contra sus ojos, y tiene el tiempo de echarse atrás y cubrirse con la mano izquierda que es su mano, que es todo lo que le queda para que lo defienda" (CC I: 312).

El fragmento citado anticipa el ápice del clímax ascendente del texto, esto es, el forcejeo entre las manos de Dina y Lucho cuya víctima acabará siendo la misma joven. Ante la insistencia de la mujer por tener luz, Lucho se decide a buscar a oscuras los fósforos que la mano de Dina, ya definitivamente rebelde, ha tirado en una esquina de la habitación. En este instante, el hombre siente "garfios que le 
corrían por la espalda, subiendo hasta la nuca y el pelo" $(1979: 141)^{13}$, mientras Dina le grita que busque la luz del rellano de la escalera. La escena que sigue muestra la definitiva fractura ontológica del sujeto y de su voluntad:

El empellón lo dejó [a Lucho] solo frente a un jadeo, algo que temblaba ahí al lado, muy cerca; estirando los brazos avanzó buscando una pared, imaginando la puerta; tocó algo caliente que lo evadió con un grito, su otra mano se cerró sobre la garganta de Dina como si apretara un guante o el cuello de un gatito negro, la quemazón le desgarró la mejilla y los labios, rozándole un ojo, se tiró hacia atrás para liberarse de eso que seguía aferrando la garganta de Dina, cayó de espalda en la alfombra, se arrastró de lado sabiendo lo que iba a ocurrir, un viento caliente sobre él, la maraña de uñas contra su vientre y sus costillas, te dije, te dije que no podía ser, que encendieras la vela, buscá en seguida la puerta, la puerta. ${ }^{14}$ (CC II: 122)

Las líneas citadas son decisivas a raíz de la dinámica fantástica que encierran; en particular, la ruptura definitiva de la causalidad se condensa en los dos periodos marcados.

Desde el comienzo, el sujeto de toda la oración parece ser Lucho, quien recibe el empujón, estira los brazos para buscar la pared y con una mano toca algo caliente que lo evita. Siguiendo esta lógica, es la otra mano del hombre que no busca la puerta la que retiene la garganta de Dina y que provoca la reacción de la mano de la mujer, que, para defenderse, quema la cara de Lucho. Sin embargo, cuando Lucho se echa de espaldas, lo hace para liberarse de su propia mano aferrada a la garganta de la mujer; lo que el narrador había definido como "su otra mano [de Lucho]", ahora ya no se concibe como suya sino que, abrazando una perspectiva interna, se define como "eso". El pasaje del adjetivo posesivo al pronombre neutro sugiere el quiebre de la identificación del hombre con su cuerpo y la apropiación de este por parte de la otredad fantástica.

El contacto entre la mano de Lucho y la garganta de Dina posibilita la cadena de intercambios simbólicos que permite el pasaje de lo fantástico abyecto del cuerpo de Dina al de Lucho y, de ahí, a la totalidad de la realidad fictiva. Después de la lucha, la mujer se queda como voz sin cuerpo, adueñada definitivamente de "eso" que viene de otro lado, y que domina ominosamente la voluntad de las manos suyas y de Lucho. La voz de Dina queda suspendida en la oscuridad, así como en la oscuridad de la habitación logrará encerrarla Lucho, metáfora del sujeto desposeído del dominio sobre su cuerpo, prisionero del "continente negro de lo fantástico" (Bozzetto 242).

La oscuridad a la que varias veces se alude en el relato -durante y después de la unión sexual, y al final del relato en el encierro de la joven en el piso- permite introducir el elemento del vacío semántico y sintáctico fundante según Campra

\footnotetext{
${ }^{13}$ La referencias a los garfios de Dina vincula su mano diabólica a la mano del protagonista de "No se culpe a nadie", la cual, independiente de la voluntad de su dueño, le araña y le pellizca y, cuando al final la cabeza del hombre consigue salir del asfixiante jersey es para encontrarse con cinco uñas negras que apuntan a sus ojos y que le empujan hacia la muerte.

${ }^{14}$ El énfasis es mío.
} 
(1991; 2008; 2014) del mecanismo de lo fantástico en la literatura de la segunda mitad del siglo XX.

La joven está poseída por lo fantástico y desposeída del dominio sobre su cuerpo. A la mirada parcial le corresponde el discurso zurdo/diagonal/cojo, ya que las frases acaban sintácticamente pero no semánticamente: "Pero hay días en que. Sí, días. Y noches" (CC II: 117) y más adelante "Entiéndame, quiero decir que." (CC II: 118). La omisión de la otra parte del discurso también refleja una perspectiva ambivalente ya que es a la vez tentativa de eliminación de lo incomprensible e imposibilidad de abarcarlo lingüísticamente. Al mismo tiempo, la afasia de Dina subraya una vez más la dialéctica entre apropiación y expropiación que, según Agamben, constituye la problemática relación del sujeto con el lenguaje y con el cuerpo propio, ambos elementos inapropiables. La frase trunca que pronuncia la mujer no solo remite a lo innombrable del acontecimiento fantástico, sino que también describe la relación con su cuerpo como "esfera opaca de conocimiento" (Agamben 116), eso es, el cuerpo es algo no-conocible, algo que no se traduce en ningún caso en algo que podamos dominar.

La palabra en el mundo alterado por lo fantástico está destituida; ya no es, como quiere Merleau-Ponty (1994: 200-201), "una modulación sincrónica de la existencia del sujeto", que designa la presencia del pensamiento del sujeto en el mundo sensible, sino que se puede convertir en algo inaccesible y que requiere un esfuerzo, tal vez imposible de hacer, para ser asida. El sujeto ya no es capaz de transformar el silencio en palabra, sino que esta deja lugar a la afasia, que adquiere los tintes de un quiebre, es figura mortífera. Sin embargo, si el silencio apunta a la cara ominosa de la realidad, al mismo tiempo, constituye una huella en los cuentos de los ataques antiverbales que caracterizan experimentos narrativos como Rayuela, Libro de Manuel, 62. Modelo para armar y los libros irregulares como La vuelta al día en ochenta mundos, Último round, Prosa del observatorio. Serían la otra cara de esa guerra abierta a las palabras como "mentiras petrificadas" (Scholz 2000: 86$)^{15}$, que configura la rebeldía del autor en contra de estructuras lingüísticas consideradas ineficaces como medio de comunicación, rebeldía que es manifestación de la crisis del hombre moderno.

\section{Piel a piel}

La interrelación entre miradas y manos toman direcciones opuestas en los dos cuentos considerados, ya que en "Ómnibus" las miradas triunfan en su carga subversiva, mientras que en "Cuello de gatito negro" son cada vez más neutralizadas por la bestialidad ominosa que domina los actos de Dina. Queda establecida en los dos relatos una cadena somática constituida por las miradas y las manos de los personajes que posibilita el intercambio simbólico entre los dos niveles de realidad. Del análisis de los dos cuentos considerados, la mirada aparece

\footnotetext{
${ }^{15}$ En este sentido, coincidimos con László Scholz $(1977 ; 2000 b)$ en rechazar la existencia de dos ramas en la producción del autor - oras que respetan las convenciones del género y otras que las transgreden- cuyo parteaguas está constituido por la experimentación con el lenguaje. En este sentido, concebimos la ruptura sintáctica y el silencio semántico como estrategias para deconstruir el lenguaje y volver, de este modo, a plantear la problemática lingüística.
} 
como un dispositivo que se bloquea; deja de ser productor de un saber y un poder omnicomprensivos que conforman una subjetividad coherente y sólida, y remite, en cambio, a un sujeto fragmentario e indefinible. Lo fantástico se apropia del dispositivo visual que define la ontogénesis del sujeto e invalida su acción todopoderosa, subvirtiéndola.

En "Ómnibus" las miradas se posan en las manos vacías de Clara y del joven y, al hacerlo, se convierten en el catalizador de la amenaza fantástica ${ }^{16}$, ya que suscitan en los protagonistas "la sensación de no pertenecerse más" a sí mismos (Le Breton 1999: 196), de estar completa e irremediablemente influenciados a partir de ese momento; al mismo tiempo, las manos de los protagonistas entrelazadas entre ellas representan también la angustia derivada de dicha amenaza. En "Cuello de gatito negro", son las manos de Dina las que vehiculan la transgresión del orden establecido ya que se mueven solas llegando a atacar a Lucho y a matar a la misma joven, mientras que las miradas se convierten en testigos impotentes de la violencia que derriba su realidad. También en "El ídolo de las cícladas", el trastocamiento ontológico se cumple al final del relato a través de las manos de Somoza y Michel que luchan entre ellos y es precisamente este contacto que permite la transferencia de la posesión demoníaca del primero al segundo. En ese cuento, sin embargo, lo fantástico llega a coincidir con la totalidad de los cuerpos de los protagonistas porque en ellos se condensan la intencionalidad, la transgresión y el efecto fantásticos; a partir y a través del cuerpo, lo sobrenatural se irradia al espacio, al tiempo y a la acción dando lugar, en el desenlace, a una superposición espacio-temporal.

Los franceses Morand y Thérèse y el argentino Somoza son tres arqueólogos que durante una excavación en Grecia encuentran una estatuilla de mármol, en la que identificarán una representación de Heghesa, antigua deidad griega del periodo de las Cícladas. Si los franceses piensan en este descubrimiento en términos estéticos y de ganancia económica, Somoza percibe una llamada y, entre la ensoñación y el juego, se pregunta si a fuerza de mirar la estatua, de tocarla, no podría haber en algún momento una abolición de las fronteras y la posibilidad de establecer un contacto directo con ella. Ya en París, Morand recibe una llamada de Somoza quien le pide que vaya urgentemente a su taller. El francés decide ir y, aparentemente sin razón, le dice a Thérèse que vaya a buscarlo dos o tres horas después.

Cuando el joven llega al taller del amigo, Somoza se encuentra en un estado de gran excitación y le cuenta al amigo que el contacto prolongado con la estatuilla ha generado un grado de familiaridad que ha franqueado las distancias permitiéndole pasar del otro lado. Ante la petición de más explicaciones por parte del escéptico Morand, se lee lo siguiente:

Siempre sentí que la piel estaba todavía en contacto con lo otro. [...] Junto al idolo, alzó una mano y la posó suavemente sobre los senos y el vientre. La otra acariciaba el cuello, subía hasta la boca ausente de la estatua, y Morand oyó

\footnotetext{
${ }^{16}$ Lo fantástico se queda en el relato como amenaza, es decir, como algo a punto de acontecer pero que, en realidad, queda en vilo. Como nota Mario Benedetti, en “Ómnibus”, lo fantástico está dado sólo por esta cosa insólita, misteriosa, innominada, que siempre parece a punto de desencadenarse y que, sin embargo, no se desencadena; lo fantástico no es lo que ocurre sino lo que amenaza ocurrir (10).
} 
hablar a Somoza con una voz sorda y opaca, un poco como si fuesen sus manos o quizá esa boca inexistente las que ahora empezaban a hablar de las cacerías en las cavernas del humo, de los ciervos acorralados, del nombre que sólo debía decirse después, de los círculos de grasa azul, de los ríos dobles, de la infancia de Pohk, de la marcha hacia las gradas del oeste y los altos en las sombras nefastas. Se preguntó si llamando por teléfono en un descuido de Somoza, alcanzaría a prevenir a Thérèse para que trajera al doctor Vernet. ${ }^{17}$ (CC I: 351 )

La "boca ausente", al que se hace referencia en el párrafo citado, se carga de polisemia ya que, a un nivel extratextual, remite a los trazos sumamente estilizados que caracterizan los rostros de las estatuillas de los ídolos de las Cícladas; mientras que, a nivel simbólico, la ausencia de una boca bien definida y reconocible funciona en el texto como metonimia del cuerpo de la estatua en tanto simulacro sin vida propia. Precisamente a raíz de la indescifrabilidad del rostro y del vacío vital, la estatua puede tomar posesión del cuerpo de quienes estén en contacto con ella, Somoza en ese caso, para llevar a cabo el sacrificio humano. El cuerpo del personaje se ha convertido en el trámite de la posesión por parte la deidad.

El contacto físico con la estatuilla coincide para Somoza con el acceso a ese otro lado lejano y vedado a los demás: "[Morand] Nunca supo de dónde había salido el hacha de piedra que se balanceaba en la mano de Somoza" (CC I: 352). Es así que éste le anuncia al amigo que se está aproximando el momento del sacrificio que brindaría la sangre necesaria a la diosa y, mientras tanto, se va quitando la ropa y acercándose a él con el arma en la mano. La escena desemboca en la lucha entre los dos que acaba con la muerte de Somoza por obra de la misma hacha que recae sobre él. Morand intenta recuperarse pensando en Thérèse que está a punto de llegar y mira a la estatua; es precisamente la visión de la estatua manchada de sangre lo que determina el cambio en el personaje:

Mientras arrastraba por un pie el cuerpo de Somoza hasta exponerlo de lleno a la luz del reflector, pensó que no le sería difícil demostrar que había obrado en legítima defensa [...] Agachándose, mojó las manos en la sangre que corría por la cara y el pelo del muerto, mirando al mismo tiempo su reloj pulsera que marcaba las siete y cuarenta. Thérèse no podía tardar, lo mejor sería salir, esperarla en el jardín o en la calle, evitarle el espectáculo del ídolo con la cara chorreante de sangre, los hilillos rojos que resbalaban por el cuello, contorneaban los senos, se juntaban en el fino triángulo del sexo, caían por los muslos. El hacha estaba profundamente hundida en la cabeza del sacrificado, y Morand la tomó sopesándola entre las manos pegajosas. Empujó un poco más el cadáver con un pie hasta dejarlo contra la columna, husmeó el aire y se acercó a la puerta. Lo mejor sería abrirla para que pudiese entrar Thérèse. Apoyando el hacha junto a la puerta empezó a quitarse la ropa porque hacía calor y olía a espeso, a multitud encerrada. Ya estaba desnudo cuando oyó el ruido del taxi y la voz de Thérèse dominando el sonido de las flautas; apagó la luz y con el hacha en la

\footnotetext{
${ }^{17}$ El énfasis es mío.
} 
mano esperó detrás de la puerta, lamiendo el filo del hacha y pensando que Thérèse era la puntualidad en persona. ${ }^{18}$ (CC I: 353 )

El párrafo citado es ejemplar porque muestra la metamorfosis gradual que sufre Morand paralelamente a la temporalidad de su espacio. A la preocupación inicial por Thérèse, indicio de su actitud todavía racional, sigue una serie de acciones que no tendría que haber hecho de acuerdo con su lógica sostenida a lo largo de todo el relato: en el mismo instante en que piensa llamar a la policía, está metiendo las manos en la sangre del amigo y empuja su cadáver, dejando huellas digitales sobre el mismo. Al final, el hecho de que Morand oiga a la vez la voz de la joven -del lado de acá-, y el sonido de las flautas -el lado de allá- representa la marca definitiva de la contaminación simbólica entre los dos niveles de realidad.

En este relato, una vez más el cuerpo se convierte en trámite privilegiado para la transmisión de lo fantástico, gracias a un proceso que me gusta definir cadena simbólica, que se establece con el contacto físico entre los personajes. Morand hereda de Somoza la función de sacerdote de Haghesa y sufre el pasaje de un estadio racional a otro irracional y sobrenatural, que culmina en el desenlace del relato cuando el personaje se prepara para acoger ya no a Thérèse sino a la próxima víctima.

En este contexto, el cuerpo de los protagonistas de los cuentos fantásticos de Julio Cortázar no son dueños de su cuerpo, sino que se descubren desposeídos del mismo por la dinámica fantástica ${ }^{19}$, cuyo origen queda siempre inalcanzable de acuerdo con las pautas del "género". Su cuerpo deja de ser una realidad natural y aislada en su singularidad, como quiere el pensamiento moderno, para convertirse en una relación -amenazante y amenazadora- con lo Real, es decir la cara oculta de la realidad. Es este sentido, me apoyo en las teorías freudiana y lacaniana acerca de lo Real. En Más allá del principio de placer (1920), Freud atribuye a lo real las propiedades de fijación y repetición, ya que lo define como aquello que reaparece aunque el sujeto no quiera que aparezca, y que vuelve siempre al mismo lugar, aun cuando perturba la homeostasis del sujeto y su tranquilidad. Y vuelve a veces con una sensación que, como lo dice el propio Freud, le crea al sujeto una impresión demoníaca.

En la elaboración lacaniana de lo real freudiano, este es lo que vuelve siempre al mismo lugar, de acuerdo con Freud, pero presupone, además, el "choque con algo" ${ }^{20}$ y adquiere también una dimensión de imposibilidad, es decir, que no tiene

\footnotetext{
${ }^{18}$ El énfasis es mío.

${ }^{19}$ Ya Campra habla de usurpación al analizar el relato "Lejana" (1951); sin embargo, el presente estudio pretende profundizar los mecanismos narrativos en que la desposesión se articula en los textos fantásticos del autor.

${ }^{20}$ Según Lacan, toda realidad humana está organizada en tres órdenes: lo imaginario, lo simbólico y lo real. En este sentido, "Lo real es, o la totalidad, o el instante desvanecido... En la experiencia analítica, para el sujeto, es siempre el choque con algo, por ejemplo: el silencio del analista" (1953: 34). Lo real en Lacan es un término que se opone a realidad. Lo real, sin embargo, empieza a asomar más claramente a fines del Seminario II y en el Seminario III, donde aparece no ya como aquello que el psicoanálisis no puede alcanzar porque es un real externo a la palabra y al sujeto de la palabra, sino como aquello que vuelve siempre al mismo lugar. Al respecto, Lacan metaforiza lo real con los astros, para subrayar como rasgo característico la fijación y la inamovibilidad. A este carácter, al mismo tiempo y de acuerdo con la metáfora de las estrellas, lo real se califica como algo que vuelve cíclicamente, es decir, responde a cierta ciclicidad; con lo cual, de acuerdo con la teoría freudiana expresada sobre todo en Más allá del principio del placer, al carácter de fijación se añade el de repetición.
} 
posibilidad de resolución lingüística. De aquí el recurso a la metáfora para aludir a lo real, que incluso lo moviliza, pero que no lo alcanza a definir ${ }^{21}$. Lo Real es algo que reaparece aunque el sujeto no quiera que aparezca, es lo que aflora destrás de la ausencia de razones que expliquen las miradas adversas de los personajes en "Ómnibus", del inquietante pronombre "eso" que Lucho atribuye a sus manos en "Cuello de gatito negro", y detrás de la alusión al contacto con "lo otro" de la sugerente frase de Somoza en "El ídolo de las cícladas".

Real y fantástico coinciden en tanto que se sancionan como algo en última instancia inabarcable por el lenguaje (Campra 1991), y que se expresa metonímicamente a través del efecto que tiene sobre el cuerpo del personaje. Dicha coincidencia, además, es corroborada por el mismo Cortázar, quien en la clase de literatura dictada en Berkley define su concepción de lo fantástico en estos términos: "[...] desde muy niño lo fantástico no era para mí lo que la gente considera fantástico; para mí era una forma de la realidad que en determinadas circunstancias se podía manifestar [...]" (2017: 50).

Punto de conjunción entre dos órdenes, así como lo era en las sociedades tradicionales entre naturaleza y cultura, el cuerpo traduce, en el sentido etimológico del término, lo fantástico en la realidad, eso es, lo transporta y expresa ahí donde el lenguaje verbal sella su derrota. Este concepto de transferencia de lo fantástico a la realidad a través de la mediación activa del cuerpo propio del personaje remite al concepto clave, ya citado en la introducción, de la semiotización del cuerpo y la somatización de lo fantástico.

El cuerpo en los relatos de Cortázar se descodifica - es decir, ya no es domesticado y reducido a reaccionar a estímulos exteriores-, y se recupera su capacidad de producir aquel lenguaje que surge de la utilización de sí mismo como sistema de signos para producir significados. En cuanto zona que genera sentido, el cuerpo es una "interlengua" que permite la circulación de los símbolos gracias al significado fluctuante que es el cuerpo mismo. En este sentido, el cuerpo engendra la dialéctica entre familiaridad y extrañeza, ya que habita el mundo como modelo compartido, a la vez que se abre y remite a su polisemia. Es precisamente porque se trata de un significado fluctuante por lo que el cuerpo puede trasladar un orden simbólico en otro.

En los cuentos de Julio Cortázar, el cuerpo constituye aquel "punto vélico" del que habla el mismo Cortázar (1967: 74) y que retomará Morillas (1991: 100), es decir espacio de convergencia donde la ruptura del orden paradigmático permite el acceso a otro ajeno a la rutina y a la convención; se convierte, de este modo, en una manera de expresar, dramatizándolo, lo indescifrable que es lo fantástico.

\footnotetext{
${ }^{21}$ En este sentido, razonar en términos psicoanalíticos sobre la concepción de la realidad en Julio Cortázar -como relación dialéctica entre real vs realidad o, mejor dicho, como realidad sensible que deja entrever su nivel más profundo que sin embargo está aquí- equivale a la concepción que los surrealistas tenían de la realidad y de la conducta humana a través del arte. Como bien subraya Scholz, su "concepción de la realidad "amplia" coincide básicamente con la "surrealidad" entendida como una superrealidad que abarca mucho más que lo que los realistas pensaron. Esta realidad "absoluta" como la llamó Breton borra los límites falsos de lo real e irreal, objetivo bien evidente también en la poética de Cortázar" (Scholz 2000: 74). En ese sentido, es importante también subrayar la idea expresada por Graciela de Sola (1968: 138 y ss.) y retomada por László Scholz del "carácter profundamente humano de su cosmovisión", ya que "Cortázar ha realizado en parte el deseo de los surrealistas de formar con el arte un principio de vida más que un nuevo arte” (2000: 77).
} 
Una estética de la desapropiación parece atravesar los relatos fantásticos de Julio Cortázar, ya que, como vio el sujeto, es desapropiado de su cuerpo como resultado de la transgresión fantástica. En lo fantástico el cuerpo del personaje deja de ser factor de individuación (Durkeim, Le Breton), ya que el personaje es desposeído de su cuerpo, que, a su vez, se convierte en una zona liminar de contaminación. Al mismo tiempo, dicha expropiación del cuerpo por parte de lo fantástico implica también, a la inversa, una restitución del cuerpo que aparece cambiado. Si el cuerpo individual inaugurado por la modernidad es un cuerpo listo, moral, sin asperezas, limitado y reticente a toda transformación eventual (Le Breton 2012: 32), en cambio, el cuerpo apropiado por la dinámica fantástica será un cuerpo provisorio, siempre en la instancia de la transfiguración y de la performatividad. Se pasa de un cuerpo aislado, separado de los demás, en posición de exterioridad respecto al mundo y encerrado en sí mismo, a un cuerpo desbordado que vive -o que está obligado a vivir- su expansión hacia afuera.

El cuerpo humano, con el ajuar de sus sentidos, percepciones y reacciones, funciona como una máscara de lo fantástico, pues si, por un lado, revela la presencia de lo ominoso, por el otro, siguen ocultando su sustancia, y constituye la apariencia de una "cosa en sí" que adolece de profundos desgarramientos. Esto remite al problema nietzscheano de la forma como disfraz, que se traduce en la narrativa de Cortázar, a mi manera de ver, en la cara escondida de la realidad que se encubre detrás de lo fantástico, o de lo fantástico como máscara ${ }^{22}$ de lo real freudiano y lacaniano. La naturaleza del cuerpo como máscara se desvela a través del desgarramiento de la lógica interna del relato y, en este marco, trabaja como instrumento para apuntar a la originaria no unidad del principio primordial de las cosas, la duplicidad insuprimible del ser, el "rechazo de la unidad de lo uno" (Vattimo 46), porque puede haber, en palabras del mismo Cortázar, "una realidad más grande, más elástica, más expandida, donde entraba todo" (2017: 50).

A mi manera de ver, el trabajo con el cuerpo en los cuentos fantásticos de Julio Cortázar participa de la tentativa de desenmascaramiento puesta en acto por las transgresiones lingüísticas de las formas del mundo como binomio de verdades y mentiras socialmente reconocidas y definidas; $y$, al mismo tiempo, del mundo de las formas, que procede de exigencias inmediatas de seguridad y dominio de la realidad externa (parafraseando a Vattimo 132). La libertad como criterio ontológico se relaciona con "la expresión de esferas que fueron consideradas "tabú" (Cortázar insiste también en la descripción del microcosmos humano, del erotismo [...])" (Scholz 2000: 72); mientras que la reivindicación de libertad formal se conecta al requisito cortazariano fundamental de la disolución de los géneros literarios ${ }^{23}$. Así las cosas, es imposible no ver detrás de la rebeldía formal el rastro de aquel descontento con respecto a las artes como tales y con respecto al

\footnotetext{
${ }^{22}$ De acuerdo con Vattimo, no es oportuno hablar de disfraz como sinónimo de máscara, más bien como su antónimo, ya que el disfraz, a diferencia de la máscara, deja intacta y exalta la individualidad determinada de quien lo asume (Véase Vattimo: 63-65).

${ }^{23}$ Con respecto a la forma como problema, se remite a la acertada reflexión de Carlos Fuentes acerca de Rayuela adscribible a una tradición específicamente argentina a la vez que como anti-novela.
} 
establishment de la literatura que manifiestan las neo-vanguardias europeas de los años sesenta ${ }^{24}$.

En este contexto hago mías las palabras que Ernesto Sábato dedica a Rimbaud, Dostoievsky y Joyce, para afirmar que el arte narrativo de Julio Cortázar utiliza el cuerpo como palimpsesto a través del cual lo fantástico actúa como dinamita que hace estallar los paisajes convencionales para poner al desnudo las verdades últimas, y muchas veces atroces, que hay en el subsuelo del hombre (155).

\section{Hacia una poética de la disonancia}

La atención en el cuerpo y en las dinámicas físicas -los sentidos, los movimientosadhiere a la que Graciela de Sola define una "épica mínima" refiriéndose a la narrativa de Cortázar (1968: 46), y en particular al cuento "Ómnibus", y, al mismo tiempo, concilia dicha conformación narrativa con la insistencia en la figura como elemento estructural de su concepción literaria. En ese sentido, el personaje participa de la construcción figurativa del autor que se extiende también a la producción fantástica; valiéndome de las palabras de Morelli en el capítulo 116 de Rayuela, los personajes acceden a la condición de figura "donde todo vale como signo y no como tema de descripción" (659).

Mano y mirada constituyen los elementos corporales que más anclan al ser humano en su realidad, como bien explica Merleau-Ponty: "Sin la exploración de mi mirada o de mi mano, y antes de que mi cuerpo sincronice con él, lo sensible no pasa de ser una vaga solicitación" (1994: 229). En los tres cuentos considerados estos dos elementos son los que subtienden los cambios que van aconteciendo y son las que permiten que lo fantástico deje de ser una "vaga solicitación" para convertirse en un fantástico "realizado" (Pezzoni: 303).

La reciprocidad que caracteriza el intercambio simbólico está finalizada a evitar, según Galimberti, la acumulación del valor en un solo polo (por ejemplo del lado de la vida en contra de la muerte o al revés), acumulación que resultaría funesta para la armonía social; en este sentido, en la retórica fantástica de Julio Cortázar, el intercambio simbólico entre los dos niveles ontológicos distintos que el cuerpo del personaje posibilita o registra pretende desarmar el valor absoluto atribuido al paradigma epistemológico de realidad construido por el occidente post cartesiano, como resultado del cese de la actividad simbólica. En este sentido, devolver al cuerpo su dimensión simbólica significa abrirlo a la disonancia, es decir a la contradicción de la armonía.

En este sentido, en la narrativa fantástica de Julio Cortázar parece estar articulada sobre y remitir a la figura -para utilizar un término querido al autor- de la disonancia, según la formulación de Adorno en su Teoría estética es la verdad sobre la armonía (190). En los cuentos analizados no se presenta reconciliado lo

\footnotetext{
${ }^{24}$ Las neo-vanguardias europeas aparecen después de un largo período de estancamiento (1945-1960). La explosión sucedió contra los realismos considerados agotados e insuficientes y, sobre todo, contra las vanguardias que se habían ajustado al mundo aburguesado traicionando sus propios principios y su razón de ser. Los acontecimientos políticos y -sociales de los años cincuenta -Argelia, Cuba, Santo Domingo, Chinaindicaban con gran evidencia que el establishment de la posguerra acababa de llegar a su fin y que el equilibrio no era ya sino aparente (véase Scholz 2000: 78).
} 
que no lo está (como quería la armonía de la estética clásica). Parafraseando al filósofo, en este sentido el cuerpo es el "coeficiente de fricción de la armonía" (Adorno 190). Si la armonía traduce la apariencia a que debería tender la obra de arte, la disonancia consiste en la sustancia reprimida de su expresión.

A nivel semántico, por ejemplo en "Ómnibus", las manos vacías constituyen la disonancia con respecto a la lógica extraña que dominaba el espacio angustioso del vehículo, así que agarrarse mutuamente significa para los personajes hacer frente a este vacío. A nivel sintáctico y verbal, la disonancia se logra a través de la adjetivación. El adjetivo no sirve para reafirmar el sustantivo, sino que lo lleva a un terreno desconocido, aparta el sustantivo de sí mismo y lo convierte en extraño con respecto a sí mismo. La boca de la estatua es "ausente" e "inexistente", la voz de Somoza se hace "opaca", el olor que se desprende de las margaritas es "nauseabundo". A través de la impropiedad semántica, la disonancia se eleva a cifra estilística. Nada es lo que era.

El giro que le da Cortázar es que la pérdida de unidad a la que la disonancia apunta ya no es algo de lo que huir, sino el único tema digno de ser tratado y eso se ve en el hecho de que la disonancia no se resuelve y el tejido semántico se rasga y nos habla solo a través de la separación.

Estas reflexiones llevan a un elemento crucial que subyace a los cuentos fantástico y a la poética cortazariana: el tema del conocimiento. En estos cuentos, el acto de conocer vuelve a ser una modalidad física de apropiación y no un acto puramente intelectual, de un yo ontológicamente diferente de su cuerpo. Según Bessière, lo fantástico "dramatiza la constante distancia entre el sujeto y lo real, por eso siempre aparece ligado a las teorías sobre los conocimientos y las creencias de una época", y se ubica, por lo tanto, en esa zona de inabarcabilidad cognoscitiva que queda al margen del rayo de acción de cualquier nuevo paradigma de realidad $^{25}$. Así, a raíz de esta distancia, Cortázar propone a través de su narrativa otra forma de conocimiento, es decir, frente al saber que coloca fuera de sí el objeto, se postula el entendimiento analógico de la participación y la posible y sobrecogedora identidad con el objeto.

\section{Referencias bibliográficas}

Baudrillard, Jean, "El cuerpo o el osario de signos", en El intercambio simbólico y la muerte. Caracas: Monte Ávila Editores, 1980 [1979], pp. 117-142.

Bessière, Irène, "El relato fantástico: forma mixta de caso y adivinanza", en David Roas (comp.). Teorías de lo fantástico. Madrid: Arco/Libros, 2001, pp. 83-104.

Bhabha, Homi. El lugar de la cultura. Buenos Aires: Manantial, 2002 [1994].

Bozzetto, Roger, “¿Un discurso sobre lo fantástico?”, en David Roas (comp.). Teorías de lo fantástico. Madrid: Arco/Libros, 2001, pp. 223-242.

Campra, Rosalba, "Los silencios del texto en la literatura fantástica", en Enriqueta Morillas Ventura (ed.). El relato fantástico en España e Hispanoamérica. Madrid: Sociedad Estatal Quinto Centenario, 1991, pp. 49-73.

—Territorios de la ficción. Lo fantástico. Sevilla: Renacimiento, 2008.

\footnotetext{
${ }^{25}$ En este sentido, concordamos con Olea Franco en que el texto fantástico no cuestiona la realidad en sí, sino el "paradigma de realidad" mediante el cual los personajes se relacionan con su entorno inmediato (2004: 59).
} 
- Cortázar para cómplices. Madrid: Del Centro Editores, 2009.

Cortázar, Julio. La vuelta al día en ochenta mundos. México: Siglo XXI, 1984 [1967].

-62 / modelo para armar. Buenos Aires: Alfaguara, 1995 [1968].

-Cuentos completos. Vols. I-II. Madrid: Alfaguara, 2015.

- Clases de literatura. Berkeley, 1980. Buenos Aires: Alfaguara, 2017.

Filer, Malva E., "La ambivalencia de la mano en la narrativa de Julio Cortázar", en Jaime Alazraki, Uvar Ivask y Joaquín Marco (eds.). Julio Cortázar: La isla final. Madrid: Ultramar, 1983, pp. 323-334.

Frölicher, Peter. La mirada recíproca. Estudio sobre los últimos cuentos de Julio Cortázar. Zárich: Peter Lang, 1995.

Galimberti, Umberto, Il corpo. Milano: Feltrinelli, 2013.

Jackson, Rosemary. Fantasy, literatura y subversión. Buenos Aires: Catálogos, 1986.

Kristeva, Julia. Poderes de la perversión. Buenos Aires: Siglo XXI, 2004.

Lacan, Jaques. Lo simbólico, lo imaginario y lo real. Conferencia dictada el 8 de Julio de 1953. Trad. de Ricardo E. Rodríguez Ponte. Escuela Freudiana de Buenos Aires, 1953. Disponible en: http://e-diciones-elp.net/images/secciones/documentos/L-53-07-08.pdf.

Le Breton, David. Antropología del cuerpo y modernidad. Buenos Aires: Nueva Visión, 2012.

Lugnani, Lucio, "Verità e disordine: il dispositivo dell'oggetto mediatore", in Remo Ceserani, Lucio Lugnani e Emanuela Scarano (eds.). La narrazione fantástica. Pisa: Nistri-Lischi, 1983, pp. 177-288.

Merleau-Ponty, Maurice. Fenomenología de la percepción. Barcelona: Península, 1994.

Morillas Ventura, Enriqueta (ed.). El relato fantástico en España e Hispanoamérica. Madrid: Sociedad Estatal Quinto Centenario, 1991.

Olea Franco, Rafael, "El concepto de literatura fantástica", en En el reino fantástico de los aparecidos: Roa Bárcena, Fuentes y Pacheco. México D.F.: El Colegio de México, 2004.

Pezzoni, Enrique, "Cortázar: una relectura de sí mismo", en El texto y sus voces. Buenos Aires: Eterna Cadencia, 2009, pp. 299-303.

Picon Garfield, Evelyn. Julio Cortázar. Nueva York: Ungar, 1975.

Prieto, René, "Julio Cortázar's perpetual exile", in Body of Writing. Figuring Desire in Spanish American Literature. Durham, NC: Duke Univesity Press, 2000, pp. 17-74.

Roas, David, "La amenaza de lo fantástico", en Teorías de lo fantástico. Madrid: Arco/Libros, 2001, pp. 7-44.

Sabato, Ernesto. El escritor y sus fantasmas. Barcelona: Austral, 2014.

Scholz, Lászlò, "Una mística profana (Julio Cortázar y la literatura sin palabras)", en Ensayos sobre la modernidad literaria hispanoamericana. Murcia: Universidad de Murcia, 2000, pp. 85-94.

Sola, Graciela de. Julio Cortázar y el hombre nuevo. Buenos Aires: Sudamericana, 1968.

Trías, Eugenio. La lógica del límite. Barcelona: Destino, 1991.

Vattimo, Gianni. El sujeto y la máscara. Nietzsche y el problema de la liberación. Barcelona: Península, 2003. 